\title{
Cardiac Function and Circulating Cytokines After Endotoxin Exposure in Neonatal Mice
}

\author{
RUPAK MUKHERJEE, TIM C. MCQUINN, MELISSA A. DUGAN, J. PHILIP SAUL, AND FRANCIS G. SPINALE
}

Divisions of Cardiothoracic Surgery [R.M., F.G.S.] and Pediatric Cardiology [R.M., T.C.M., M.A.D., J.P.S.], Medical University of South Carolina, Charleston, SC 29425; Ralph H. Johnson VA Medical Center [F.G.S.], Charleston, SC 29401

\begin{abstract}
Complications after cardiac surgery in neonates can occur because of activation of the inflammatory system. This study used lipopolysaccharide (LPS) endotoxin exposure to cause cytokine activation in neonatal mice and examine left ventricular (LV) function and the effects of antioxidant treatment on cytokine levels. Neonatal mice ( $6 \mathrm{~d}$ old) were injected with either $25 \mathrm{mg} / \mathrm{kg}$ LPS $(n=$ 13 ) or PBS ( $n=14$ ), and LV function (echocardiography) was measured at $4 \mathrm{~h}$. Plasma levels of TNF- $\alpha$, IL-4, IL-6, and IL-10 were measured at $30 \mathrm{~min}, 1,2$, and $4 \mathrm{~h}$ after injection $(n=5$ mice per group). Effects of pretreatment with $N$-acetylcysteine (NAC, 50 $\mathrm{mg} / \mathrm{kg}$ ) on cytokine levels were examined at 2 and $4 \mathrm{~h}$ after PBS or LPS ( $n=5$ mice per group). Four hours after LPS, heart rate was increased (434 \pm 14 versus $405 \pm 14 \mathrm{bpm}, p<0.05)$. LV enddiastolic dimension and ejection time were reduced with LPS (both $p<0.05$ ). LPS exposure increased plasma TNF- $\alpha$, IL-6, and IL-10 levels. NAC pretreatment attenuated the increases in TNF- $\alpha$ and IL-6 levels, but augmented IL-10 levels at $2 \mathrm{~h}$ post-LPS. LPS exposure altered cardiac performance and activated cytokines in neonatal mice, which may be ameliorated using antioxidants. (Pediatr Res 68:
\end{abstract} 381-386, 2010)

$\mathrm{S}^{\mathrm{u}}$ urgical repair of some of the most lethal and complex forms of human congenital heart disease (e.g. hypoplastic left heart syndrome, transposition of the great arteries) is initiated in the perinatal period. The postoperative state of these infants is characterized by reduced cardiac output and extensive edema (1-3). One likely mechanism for these clinical postoperative sequelae is activation of the innate inflammatory cytokine response and establishing conditions similar to those described for the fetal inflammatory response syndrome (FIRS) (4). Lipopolysaccharide (LPS) is a potent activator for FIRS (4) and is increased after surgery to repair congenital heart defects (5). Although past studies have reported that rodent fetuses exposed to LPS during the late gestational period exhibit symptoms similar to that of FIRS (6), the effects of increased LPS with respect to left ventricular (LV) pump function and the response of pro- and antiinflammatory cytokines in the neonatal period remain unknown. Accordingly, the first objective of this study was to examine the relationship of LPS exposure to indices of cardiac

\section{Received March 11, 2010; accepted June 24, 2010.}

Correspondence: Rupak Mukherjee, Ph.D., Cardiothoracic Surgery, Strom Thurmond Research Building, 770 MUSC Complex, Suite 625, Medical University of South Carolina, Charleston, SC 29425; e-mail: mukherr@musc.edu

Supported, in part, by Grants HL-45024, HL-97012, and PO1-48788 from National Heart, Lung, and Blood Institute, a VA Merit Award [to F.G.S.], and departmental funds from the Division of Pediatric Cardiology. performance and the time-dependent changes in cytokine profiles induced by LPS in neonatal mice.

One likely pathway by which FIRS may adversely affect cardiovascular performance and cytokine activation is through oxidative stress (4). A common intervention that holds clinical relevance with respect to oxidant scavenging is $N$-acetylcysteine (NAC) $(7,8)$. Although past studies simulating LPSmediated FIRS in rodents have shown improved survival with concomitant NAC treatment (7), the underlying mechanisms with respect to changes in the levels of circulating cytokines remained unknown. Accordingly, the second objective of this study was to determine the effects of NAC treatment on possible alterations in cytokine activation after LPS exposure in neonatal mice.

\section{METHODS}

Animals were treated and cared for in accordance with the National Institutes of Health Guide for the Care and Use of Laboratory Animals (National Institutes of Health, 1996). The protocol (AR2300) was approved by the Animal Care and Use Committee. Animals used in this study were 6-d-old mice ( $3.6 \pm 0.1 \mathrm{~g}, \mathrm{~F} 1$ generation) born to dams from the CD-1 strain (Charles River). The rationale for choosing this age of neonatal mice was to collect adequate amount of plasma to assay for levels of circulating cytokines.

Determination of optimal LPS dose. A wide range of LPS dosages ranging from 1 to $50 \mathrm{mg} / \mathrm{kg}$ (L2630, derived from Escherichia coli, strain 0111:B4, purified by phenol extraction; Sigma Chemical Co.-Aldrich, St. Louis, MO) were tested with respect to survival and effects on LV fractional shortening (Vevo 660, Visualsonics, Toronto, Canada) at $4 \mathrm{~h}$ after intraperitoneal injection of LPS. Anesthesia was maintained at 1.5-2.0\% isoflurane to obtain echocardiography images at baseline and after LPS exposure (minimum of 4 mice per dose). At LPS dosages of 1,2 , or $5 \mathrm{mg} / \mathrm{kg}$, there were no discernible adverse effects with respect to survival, mobility, gastrointestinal distress, or LV pump performance. All mice injected with $25 \mathrm{mg} / \mathrm{kg}$ of LPS survived through $4 \mathrm{~h}$, and the pups exhibited changes in LV mechanics in terms of reduced ejection time. With $50 \mathrm{mg} / \mathrm{kg}$ of LPS, four of the six pups had died by $4 \mathrm{~h}$ postinjection. Accordingly, the $25 \mathrm{mg} / \mathrm{kg}$ dosage of LPS was chosen for subsequent studies. Hematocrit was measured after $4 \mathrm{~h}$ of either LPS or PBS administration. The hematocrit of the LPS-treated mouse pups $(0.28 \pm 0.01, n=16)$ was similar to those administered PBS $(0.27 \pm 0.01$, $n=23, p=0.80$ ), suggesting that this dosage of LPS did not result in edema formation.

Echocardiography. Parasternal short axis and pulse wave Doppler (fourchamber view) images were recorded. Measurements from the short axis views included LV dimensions at end diastole and end systole and fractional shortening. The inflow and outflow velocity profiles recorded in the pulse wave Doppler images were used to determine R-R intervals (heart rate), isovolumic contraction time, ejection time, and isovolumic relaxation time. These echocardiographic measurements were made at baseline (preinjection) and at $4 \mathrm{~h}$ after injection of either PBS $(n=14)$ or LPS $(n=13)$.

\footnotetext{
Abbreviations: CPB, cardiopulmonary bypass; FIRS, fetal inflammatory response syndrome; LPS, lipopolysaccharide; LV, left ventricular; MIP, macrophage inflammatory protein; NAC, $N$-acetylcysteine
} 
Longitudinal measurement of cytokines/chemokines. For measurement of plasma levels of cytokines, separate cohorts of mouse pups were injected with either PBS or LPS. The volume of the injectate in each case was 0.1 $\mathrm{mL} / \mathrm{g}$ body weight $(10 \mathrm{~mL} / \mathrm{kg})$ to protect against dehydration. After injection, the mouse pups remained fasted and were housed in a thermostatically controlled chamber $\left(37^{\circ} \mathrm{C}\right)$. Terminal studies were performed at $30 \mathrm{~min}, 1,2$, or $4 \mathrm{~h}$ after injection (minimum of $n=5$ mice at each time point). At the designated time point, the mice were decapitated while anesthetized. Blood samples $(\sim 500 \mu \mathrm{L})$ were collected in an EDTA coated tube, centrifuged, and the plasma decanted. Blood samples from a separate cohort of 15 untreated mouse pups were used as referent controls.

In separate cohorts of mouse pups, NAC $(50 \mathrm{mg} / \mathrm{kg})$ was injected an hour before the administration of PBS or LPS. This dosage of NAC used was chosen based on past findings, which demonstrated that $50 \mathrm{mg} / \mathrm{kg}$ of NAC prevented LPS-induced cytokine induction in fetal mice (8). These pups were terminally studied at either $2 \mathrm{~h}$ or $4 \mathrm{~h}$ after injection of PBS or LPS ( $n=5$ mice per time point for each treatment).

Multiplex assay for cytokine/chemokine levels. Plasma levels of cytokines were determined by multiplex suspension array (BioRad and R\&D Systems), which allows for the simultaneous measurement of a large number of analytes from volume-limited samples (9). Briefly, plasma $(50 \mu \mathrm{L})$ from individual mouse pups (no pooling of blood samples was performed) was added to wells precoated with antibody-microbead complexes. Identification and quantification of the analyte/bead complexes were determined by flow cytometry with dual excitation lasers (Bio-Plex Suspension Array Workstation; BioRad) and converted to $\mathrm{pg} / \mathrm{mL}$ using precalibrated standards. Average sensitivities for cytokines were $0.3 \mathrm{pg} / \mathrm{mL}$. The cytokine multiplex assays have $<0.5 \%$ cross-reactivity and interference with the other measured analytes. Cytokines and/or chemokines measured in the plasma samples included TNF- $\alpha$, IL-4, IL-6, IL-10, macrophage inflammatory protein-1 $\alpha$ (MIP-1 $\alpha$, CCL3), and RANTES (CCL5). In addition, plasma levels of VEGF, which has been previously demonstrated to be a sensitive biomarker for hypoxia $(10,11)$, were measured using the same multiplex suspension array.

Data analysis. All of the data collected in this study were coded and the code not broken until the conclusion of the study. Echocardiographic indices of LV geometry and function were compared between the PBS and LPS groups using the $t$ test. For the cytokine measurements, a two-way ANOVA model was used to differentiate between the effects of time and LPS exposure. Post hoc mean separation was performed using Bonferroni-adjusted pairwise comparisons. Similarly, the effects of concomitant NAC treatment on LPS exposure were examined using two-way ANOVA (treatment effects: presence or absence of LPS and presence or absence of NAC). Correlations between cytokine levels and indices of LV geometry and function were examined using least squares regression analysis. All statistical analyses were performed using the STATA statistical software package (Stata Corp, College Station, TX). Values of $p<0.05$ were considered to be statistically significant.

\section{RESULTS}

Echocardiography. Compared with baseline values (405 \pm $14 \mathrm{bpm})$, there was a significant increase in heart rate for the mice in the LPS group (434 $\pm 14 \mathrm{bpm}, p<0.05$ ); the heart rate for the PBS group (414 $\pm 21 \mathrm{bpm})$ was similar to baseline values ( $p=\mathrm{NS}$ ). LV end-diastolic dimensions were smaller in LPS-exposed animals compared with baseline values and compared with the group that was injected with PBS (Table 1). LV fractional shortening was similar in the PBS and LPS groups at $4 \mathrm{~h}$ after exposure. $\mathrm{LV}$ ejection time was lower in the LPS-treated animals than the PBS-treated controls (Table 1). As a function of R-R interval, changes in ejection time were similar to baseline values in the PBS group (Fig. 1). However, in the LPS group, the slope of the relationship between ejection time and the R-R interval was lower than baseline values and the PBS group.

Temporal changes in cytokine levels. Temporal changes in the plasma levels of the cytokines/chemokines after PBS or LPS injection are summarized in Table 2. In the PBS group, there was a small, but significant, increase in plasma TNF- $\alpha$ levels and a reduction in plasma IL-10 levels at $4 \mathrm{~h}$ after injection. With LPS exposure, there were time-dependent
Table 1. Indices of LV geometry and function injection of PBS or LPS in 6-d-old mice

\begin{tabular}{|c|c|c|c|}
\hline & Baseline & PBS & LPS \\
\hline $\begin{array}{l}\text { LV end-diastolic } \\
\text { dimension }(\mathrm{mm})\end{array}$ & $1.84 \pm 0.04$ & $1.81 \pm 0.05$ & $1.51 \pm 0.07 *$ \\
\hline $\begin{array}{l}\text { LV end-systolic } \\
\text { dimension (mm) }\end{array}$ & $1.16 \pm 0.03$ & $1.13 \pm 0.05$ & $0.91 \pm 0.06^{*} \dagger$ \\
\hline Fractional shortening (\%) & $34 \pm 2$ & $33 \pm 4$ & $37 \pm 4$ \\
\hline $\begin{array}{l}\text { Isovolumic contraction } \\
\text { time }(\mathrm{ms})\end{array}$ & $15.4 \pm 1.0$ & $12.5 \pm 0.6$ & $11.4 \pm 1.5^{*}$ \\
\hline Ejection time (ms) & $53.2 \pm 3.0$ & $53.2 \pm 4.5$ & $45.6 \pm 2.5 * \dagger$ \\
\hline $\begin{array}{l}\text { Isovolumic relaxation } \\
\text { time }(\mathrm{ms})\end{array}$ & $22.8 \pm 1.7$ & $25.0 \pm 2.1$ & $24.9 \pm 2.3$ \\
\hline Sample size $(n)$ & 27 & 14 & 13 \\
\hline
\end{tabular}

Values presented as mean \pm SEM. Sample size: $n=5$ for all treatments. $* p<0.05$ vs baseline.

$\dagger p<0.05$ vs PBS group.

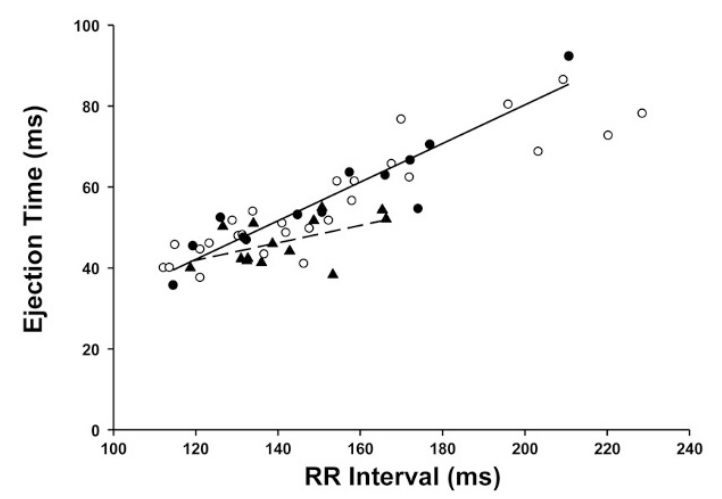

Figure 1. Effects of PBS and LPS on the relationship between R-R interval and LV ejection time. There was a significant relationship between R-R interval and ejection time at baseline $\left(y=0.37 x-0.31 ; r^{2}, 0.81 ; p<0.01\right)$. In the PBS group, the relationship between R-R interval to ejection time ( $y=$ $\left.0.48 x-15.11 ; r^{2}, 0.86 ; p<0.01\right)$ was similar to baseline values $(p=0.62)$. With LPS, the relationship between R-R interval and ejection time ( $y=$ $\left.0.22 x+16.05 ; r^{2}, 0.28 ; p<0.05\right)$ was different from baseline and the PBS group ( $p<0.01$ and $p=0.03$, respectively). $\bigcirc$, baseline; $\bullet$, PBS; $\boldsymbol{\Lambda}$, LPS.

increases in plasma levels of TNF- $\alpha$, IL-6, and IL-10 after $1 \mathrm{~h}$ after injection, and the increase in the levels of these cytokines persisted through the 4-h study period. A significant increase in the plasma levels of the chemokines, MIP- $1 \alpha$, and RANTES (or CCL5) was detected starting at $2 \mathrm{~h}$ after LPS exposure. There was an inverse relationship between MIP- $1 \alpha$ levels and the change in ejection time (Fig. 2). Furthermore, plasma IL-6 level was inversely related to LV end-systolic dimension $\left(y=-1.05 \times 10^{-5} x+1.06 ; r,-0.67 ; p<0.05\right)$ and change in ejection time $\left(y=-7.58 \times 10^{-4} x+7.08\right.$; $r,-0.72 ; p<0.05)$.

Effects of NAC on plasma levels of cytokines/chemokines. At $2 \mathrm{~h}$ after injection, concomitant NAC administration attenuated the LPS-mediated increased plasma levels of TNF- $\alpha$, IL-6, MIP- $\alpha$, and CCL-5 (Fig. 3). Conversely, plasma levels of IL-10 were increased with NAC treatment compared with LPS only values at $2 \mathrm{~h}$ after injection. At $4 \mathrm{~h}$ after LPS injection, the differences in plasma cytokine/chemokine levels with respect to NAC treatment did not attain statistical significance. Plasma levels of VEGF were lower with concomitant NAC treatment $2 \mathrm{~h}$ after LPS administration (Fig. 4). 
Table 2. Time-dependent changes in plasma cytokine levels after exposure to PBS or endotoxin (LPS) in 6-d-old mice

\begin{tabular}{|c|c|c|c|c|c|c|}
\hline & Baseline & & $30 \mathrm{~min}$ & $1 \mathrm{~h}$ & $2 \mathrm{~h}$ & $4 \mathrm{~h}$ \\
\hline \multirow[t]{2}{*}{$\mathrm{TNF}-\alpha(\mathrm{pg} / \mathrm{mL})$} & $6 \pm 5$ & PBS & $1 \pm 1$ & $1 \pm 1$ & $8 \pm 5$ & $40 \pm 9 *$ \\
\hline & & LPS & $5 \pm 1$ & $506 \pm 69 * \dagger$ & $2782 \pm 597 * \dagger$ & $9062 \pm 2168 * \dagger$ \\
\hline \multirow[t]{2}{*}{ IL-4 (pg/mL) } & $71 \pm 13$ & PBS & $82 \pm 7$ & $78 \pm 3$ & $44 \pm 12$ & $77 \pm 3$ \\
\hline & & LPS & $60 \pm 14$ & $59 \pm 3$ & $68 \pm 5$ & $75 \pm 6$ \\
\hline \multirow[t]{2}{*}{ IL-6 (pg/mL) } & $1 \pm 1$ & PBS & ND & $2 \pm 1$ & $5 \pm 5$ & $1 \pm 1$ \\
\hline & & LPS & $1 \pm 1$ & $698 \pm 137 * \dagger$ & $32040 \pm 8362 * \dagger$ & $27621 \pm 2620 * \dagger$ \\
\hline \multirow[t]{2}{*}{ IL-10 (pg/mL) } & $16 \pm 3$ & PBS & $11 \pm 2$ & $16 \pm 1$ & $13 \pm 3$ & $5 \pm 1 \dagger$ \\
\hline & & LPS & $14 \pm 3$ & $105 \pm 24 * \dagger$ & $432 \pm 18 * \dagger$ & $700 \pm 99 * \dagger$ \\
\hline \multirow[t]{2}{*}{$\operatorname{MIP}-1 \alpha(\mathrm{pg} / \mathrm{mL})$} & $124 \pm 53$ & PBS & $165 \pm 47$ & $30 \pm 18 \dagger$ & $53 \pm 30$ & $73 \pm 24$ \\
\hline & & LPS & $72 \pm 45$ & $24 \pm 14 \dagger$ & $3798 \pm 1133^{* \dagger}$ & $3382 \pm 928 * \dagger$ \\
\hline \multirow[t]{2}{*}{ RANTES (CCL5, pg/mL) } & $13 \pm 3$ & PBS & $10 \pm 1$ & $7 \pm 1$ & $7 \pm 1$ & $7 \pm 1$ \\
\hline & & LPS & $10 \pm 1$ & $10 \pm 2$ & $1030 \pm 294 * \dagger$ & $10082 \pm 1343 * \dagger$ \\
\hline
\end{tabular}

Values presented as mean \pm SEM. Sample size: $n=5$ for all treatments.

$* p<0.05$ vs baseline.

$\dagger p<0.05$ vs time-matched PBS group.

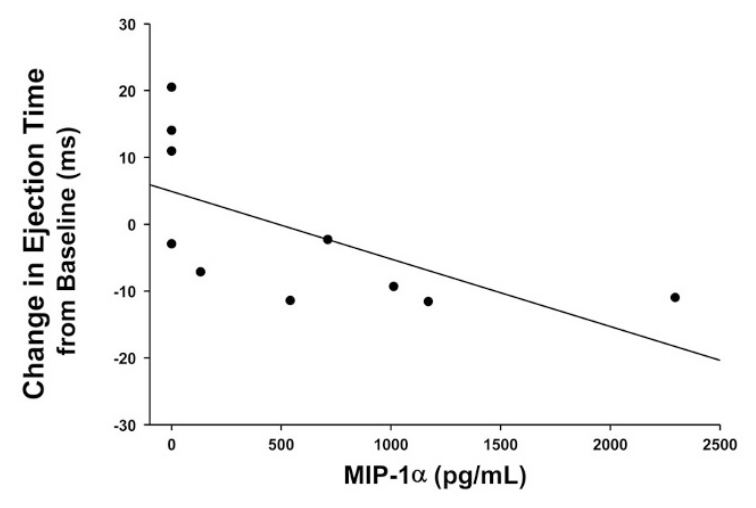

Figure 2. There was a significant inverse relationship between MIP-1 $\alpha$ levels and the change in ejection time $\left(y=-1.01 \times 10^{-2} x+4.90 ; r,-0.64\right.$; $p<0.05)$ after administration of either PBS or LPS.

\section{DISCUSSION}

Circulating levels of a number of cytokines, particularly those of the proinflammatory cytokines, are increased after exposure to LPS $(12,13)$. However, a majority of these past studies were performed in age groups that represent adults, or a mature phenotype, and in animal fetuses obtained late in the gestational period $(8,14-17)$. Although there are a few studies that have examined the effects of LPS on plasma cytokine levels in neonates (18-26), the effects of LPS-induced changes in cardiac function and the effects of antioxidant treatment on circulating levels of cytokines in neonates remained unknown. Accordingly, the objectives of this study were to determine the effects of LPS exposure to indices of cardiac performance and the time-dependent changes in cytokine profiles induced by LPS in neonatal mice. Moreover, this study examined whether treatment with the antioxidant, NAC, would alter LPS-induced changes in cytokine levels in neonatal mice. The main findings of this study were that LPS caused time-dependent increase in the levels of proinflammatory cytokines such as TNF- $\alpha$ and IL-6 as well as in the levels of the anti-inflammatory cytokine, IL-10 in neonatal mice. Moreover, LPS exposure resulted in a reduction in LV dimensions, and a reduction in LV ejection time, and the increase in circulating cytokine levels was correlated with adverse changes in cardiac performance. Concomitant treatment with
NAC attenuated the LPS-induced increases in TNF- $\alpha$ and IL-6 at $2 \mathrm{~h}$. Conversely, NAC treatment augmented the LPSinduced increase in IL-10 levels at $2 \mathrm{~h}$ after injection. These findings suggest that LPS exposure is associated with alterations of indices of cardiac performance and that antioxidants may be used to ameliorate the proinflammatory effects of LPS exposure in neonates.

LPS exposure is generally associated with a reduction in cardiac pump function in adult animal models (16). However, it must be recognized that in this study, LV fractional shortening, an index of LV pump performance, was similar between the LPS- and PBS-treated groups. There are at least two reasons for these seemingly disparate findings with respect to LV pump function between past reports and the present study: First, age-dependent differences in response to LPS exposure with respect to cardiac function cannot be ruled out. Second, it is possible that changes in cardiac function in response to LPS exposure may be time-dependent $(16,27)$. For example, in adult dogs injected with LPS, Guntheroth et al. (16) have reported that the velocity of contraction transiently increased immediately after LPS injection and then gradually declined to baseline values at $4 \mathrm{~h}$ after LPS administration. Therefore, the finding that LV pump function was not altered with LPS exposure may have been a function of the time at which the measurement was made. Future studies that examine LV pump performance at differing postinjection durations would be required to determine whether and to what degree LPS exposure alters cardiac function in neonatal mice.

In this study, LPS administration resulted in a reduction of LV dimensions and ejection time. Moreover, the slope of the relationship between $\mathrm{LV}$ ejection time and the R-R interval was reduced with LPS exposure. In light of the fact that the circulating volume was similar in animals treated with either PBS or LPS (hematocrit values were similar between groups), the relative reduction in LV ejection time was likely because of a reduction in systemic vascular resistance and/or increased systemic capacitance. Additional considerations for the reduction in LV dimensions with LPS include reduced LV filling time, because of the increase in heart rate, and a potential increase in venous dilation. Regardless of which of these above mechanisms were operative, the findings of this study 

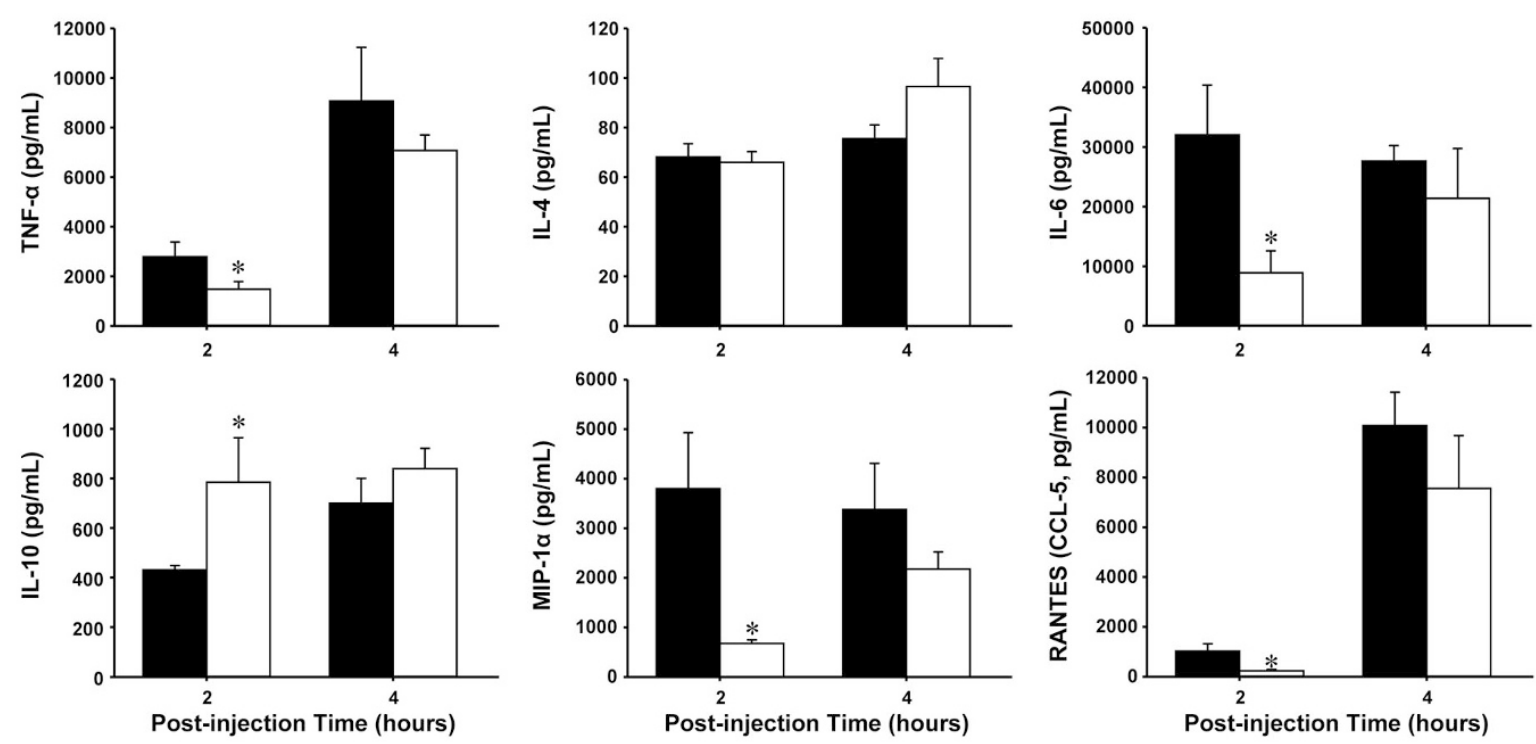

Figure 3. Effects of NAC treatment on LPS-induced changes in plasma levels of cytokines/chemokines at 2 and $4 \mathrm{~h}$ after injection. * $p<0.05 v s$ LPS only group. 口, LPS only; $\square$, LPS + NAC.

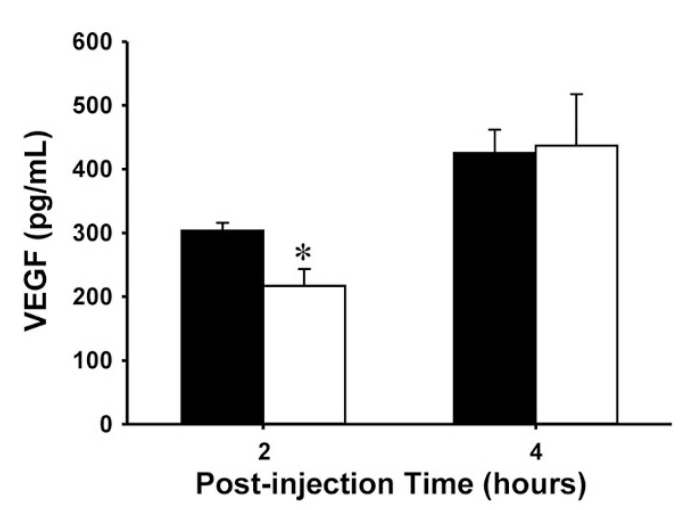

Figure 4. Effects of NAC treatment on LPS-induced changes in plasma levels of VEGF at 2 and $4 \mathrm{~h}$ after injection. * $p<0.05$ vs LPS only group. LPS only; $\square$, LPS + NAC.

provide evidence that the increase in circulating cytokines after LPS exposure was associated with adverse changes in LV geometry and pump function.

LPS has been reported to be one of the most potent stimulators of the synthesis and release of proinflammatory cytokines such as TNF- $\alpha$, IL-1 $\beta$, and IL-6 (13). In vitro studies have demonstrated that LPS can trigger the production TNF- $\alpha$ and IL-1 $\beta$ from isolated blood monocytes (28). Excessive activation of the proinflammatory cytokines can be harmful, leading to tissue damage, sepsis, and increased mortality. For example, using a panel of cytokines, $\mathrm{Ng}$ et al. (23) demonstrated that increased levels of IL-6 and RANTES could be prognostic of sepsis-induced complications. Moreover, Casey et al. (29) reported that increased levels of circulating cytokines TNF- $\alpha$, IL-1, and IL-6 correlated with higher mortality in patients with sepsis. Importantly, the response of the immune system, including that of cytokine induction, varies as a function of age $(18,19,22,24)$. Zhao et al. (18) have recently reported that elevations in plasma TNF- $\alpha$ and IL-6 levels are quantitatively higher in neonatal mice compared with adult mice. Furthermore, Cusumano et al. (22) report that neonatal mice were more susceptible to LPS-induced mortality than older mice. This study builds on these past findings by demonstrating that LPS exposure caused time-dependent increases in the plasma levels of not only the proinflammatory cytokines but also that of the anti-inflammatory cytokine, IL-10. Changes in IL-10 levels are believed to be an endogenous reaction aimed to suppress effects of proinflammatory cytokines (30). Therefore, the increase in plasma IL-10 levels observed in this study may have been, at least in part, a response to counteract the strong induction of the proinflammatory cytokines after LPS exposure.

Infusion of antioxidants can ameliorate the LPS-mediated increase in the levels of proinflammatory cytokines $(14,15)$. Whether and to what degree infusion of an antioxidant would alter cytokine induction in neonatal animals remained unknown. In this study, the antioxidant NAC was chosen for two reasons. First, NAC is a clinically relevant pharmacological agent, which is used as a mucolytic agent and to modulate inflammation in patients with cystic fibrosis $(31,32)$. Second, NAC can inhibit the induction of proinflammatory cytokines $(14,15)$. For example, Hsu et al. (14) report that in adult rats, prolonged concomitant NAC infusion attenuated the LPSmediated increase in serum levels of TNF- $\alpha$ and IL-6. Consistent with these past findings, this study demonstrated that a single bolus infusion of NAC reduced circulating levels of the proinflammatory cytokines TNF- $\alpha$ and IL- 6 at $2 \mathrm{~h}$ after LPS exposure in neonatal mice. Concomitantly, levels of the antiinflammatory cytokine IL-10 were increased with NAC treatment. IL-10 is a pleiotropic cytokine with important immunoregulatory functions and can repress the expression of inflammatory cytokines such as TNF- $\alpha$ and IL-6 (30). Therefore, the increase in plasma IL-10 levels with NAC treatment may have further potentiated a putative protective effect from LPS exposure. It is likely that these salutary effects of NAC with respect to LPS-induced cytokine induction were because 
of the antioxidant effects of NAC, evidenced by lower levels of VEGF, a sensitive and stable marker for hypoxic injury (10). However, these salutary effects of NAC treatment on circulating cytokine levels were not evident with $4 \mathrm{~h}$ of LPS exposure. A potential explanation is that plasma levels of NAC, which has a half-life of $\sim 2 \mathrm{~h}$ (33), may have been reduced to below therapeutic levels at $4 \mathrm{~h}$ after the single bolus infusion. Whether continuous infusion of NAC would provide a longer attenuation of the induction of proinflammatory cytokines in this neonatal animal model remains to be determined. Moreover, whether and to what degree the NACmediated attenuation of the levels of the proinflammatory cytokines after LPS exposure was beneficial with respect to indices of LV pump function were not determined in this study. Future studies that determine the effects of NAC with respect to the relationship between changes in plasma cytokine levels and LV pump performance are warranted. Moreover, the effects of varying NAC dosage and optimal length of NAC therapy with respect to effects on cytokine levels in neonates remain to be determined.

It must be recognized that the concentration of LPS used in this study was likely higher than that is measured clinically, even in pediatric patients who are considered to be "endotoxemic" (5). Therefore, it remains unclear whether the effects of LPS exposure on LV geometry and function that were observed in this study would be manifest with lower LPS concentrations. Accordingly, extrapolation of the results of this study to the clinical scenario must be undertaken with caution.

\section{CONCLUSIONS}

Cardiac surgery, especially those procedures that require extracorporeal circulatory support, can engender a significant inflammatory response in the immediate postoperative period (5). The use of cardiopulmonary bypass (CPB) during cardiothoracic surgery procedures, and the systemic exposure to nonbiologic surfaces, has been shown to promote edema secondary to changes in oncotic pressure and reduced lymphatic drainage and to provoke an oxidative stress response, which in turn can activate inflammatory processes $(2,3,5)$. The increased proinflammatory state has been associated with the development of a number of postprocedural complications, including myocardial injury and the low cardiac output syndrome (LCOS) (1,34). Clinical appreciation of the invocation of the inflammatory response after cardiac surgery in neonates has resulted in a number of interventions directed at its reduction. For example, modification of pump circuit surfaces, ultrafiltration strategies, leukocyte trapping filters, and glucocorticoid administration have all been described to reduce or eliminate clinical or biochemical features of the inflammatory response after CPB (35-37). A survey of 36 centers that perform pediatric $\mathrm{CPB}$ demonstrated that none of these interventions has achieved a level of standard practice in the pediatric or neonatal population (35). Therefore, there is a need for a safer and more effective anti-inflammatory strategy in pediatric patients undergoing cardiac surgery. Accordingly, the data from this study represent a step in establishing a model system for mimicking the neonatal inflammatory response LPS administration and testing the effects of NAC as a potential anti-inflammatory therapy with a benign side effect profile that has established neuroprotective effects in a perinatal model of brain injury $(8,38)$. A role for oxidative stress for complications after cardiac surgery has been demonstrated through the use of NAC (39). Specifically, in dogs subjected to $\mathrm{CPB}$, addition of NAC in the perioperative period was associated with a reduction of myocardial edema and a preservation of LV systolic function (40). In this study, pretreatment with NAC attenuated the LPS-mediated increase in the levels of the proinflammatory cytokines in neonatal mice. Thus, the use of NAC may represent a novel means of attenuating these adverse post-CPB sequelae.

\section{REFERENCES}

1. Hövels-Gürich HH, Vazquez-Jimenez JF, Silvestri A, Schumacher K, Minkenberg R, Duchateau J, Messmer BJ, von Bernuth G, Seghaye MC 2002 Production of proinflammatory cytokines and myocardial dysfunction after arterial switch operation in neonates with transposition of the great arteries. J Thorac Cardiovasc Surg 124:811-820

2. Wernovsky G, Wypij D, Jonas RA, Mayer JE Jr, Hanley FL, Hickey PR, Walsh AZ Chang AC, Castaneda AR, Newburger JW, Wessel DL 1995 Postoperative course and hemodynamic profile after the arterial switch operation in neonates and infants. A comparison of low-flow cardiopulmonary bypass and circulatory arrest. Circulation 92:2226-2235

3. Tassani P, Schad H, Schreiber C, Zaccaria F, Haas F, Mossinger H, Altmeyer S, Kohler R, Seghaye MC, Lange R 2007 Extravasation of albumin after cardiopulmonary bypass in newborns. J Cardiothorac Vasc Anesth 21:174-178

4. Gotsch F, Romero R, Kusanovic JP, Mazaki-Tovi S, Pineles BL, Erez O, Espinoza J, Hassan SS 2007 The fetal inflammatory response syndrome. Clin Obstet Gynecol 50:652-683

5. Lequier LL, Nikaidoh H, Leonard SR, Bokovoy JL, White ML, Scannon PJ, Giroir BP 2000 Preoperative and postoperative endotoxemia in children with congenital heart disease. Chest 117:1706-1712

6. Rounioja S, Rasanen J, Ojaniemi M, Glumoff V, Autio-Harmainen H, Hallman M 2005 Mechanism of acute fetal cardiovascular depression after maternal inflammatory challenge in mouse. Am J Pathol 166:1585-1592

7. Chang EY, Barbosa E, Paintlia MK, Singh A, Singh I 2005 The use of $N$-acetylcysteine for the prevention of hypertension in the reduced uterine perfusion pressure model for preeclampsia in Sprague-Dawley rats. Am J Obstet Gynecol 193:952-956

8. Paintlia MK, Paintlia AS, Barbosa E, Singh I, Singh AK $2004 N$-acetylcysteine prevents endotoxin-induced degeneration of oligodendrocyte progenitors and hypomyelination in developing rat brain. J Neurosci Res 78:347-361

9. McEvoy MD, Sabbagh MJ, Taylor AG, Zavadzkas JA, Koval CN, Stroud RE, Ford RL, McLean JE, Reeves ST, Mukherjee R, Spinale FG 2009 Aprotinin modifies left ventricular contractility and cytokine release after ischemia-reperfusion in a dosedependent manner in a murine model. Anesth Analg 108:399-406

10. Rabbani ZN, Mi J, Zhang Y, Delong M, Jackson IL, Fleckenstein K, Salahuddin FK, Zhang X, Clary B, Anscher MS, Vujaskovic Z 2010 Hypoxia inducible factor 1alpha signaling in fractionated radiation-induced lung injury: role of oxidative stress and tissue hypoxia. Radiat Res 173:165-174

11. Pawlak K, Mysliwiec M, Pawlak D 2008 Oxidative stress, phosphate and creatinine levels are independently associated with vascular endothelial growth factor levels in patients with chronic renal failure. Cytokine 43:98-101

12. Cannon JG, Nerad JL, Poutsiaka DD, Dinarello CA 1993 Measuring circulating cytokines. J Appl Physiol 75:1897-1902

13. Dinarello CA, Cannon JG 1993 Cytokine measurements in septic shock. Ann Intern Med 119:853-854

14. Hsu BG, Lee RP, Yang FL, Harn HJ, Chen HI 2006 Post-treatment with $N$-acetylcysteine ameliorates endotoxin shock-induced organ damage in conscious rats. Life Sci 79:2010-2016

15. Hsu BG, Yang FL, Lee RP, Peng TC, Harn HJ, Chen HI $2004 N$-acetylcysteine ameliorates lipopolysaccharide-induced organ damage in conscious rats. J Biomed Sci 11:152-162

16. Guntheroth WG, Jacky JP, Kawabori I, Stevenson JG, Moreno AH 1982 Left ventricular performance in endotoxin shock in dogs. Am J Physiol 242:H172-H176

17. Guntheroth WG, Kawabori I, Stevenson JG, Cholvin NR 1978 Pulmonary vascular resistance and right ventricular function in canine endotoxin shock. Proc Soc Exp Biol Med 157:610-614

18. Zhao J, Kim KD, Yang X, Auh S, Fu YX, Tang H 2008 Hyper innate responses in neonates lead to increased morbidity and mortality after infection. Proc Natl Acad Sci U S A 105:7528-7533

19. Adkins B, Leclerc C, Marshall-Clarke S 2004 Neonatal adaptive immunity comes of age. Nat Rev Immunol 4:553-564

20. Garcia AM, Fadel SA, Cao S, Sarzotti M 2000 T cell immunity in neonates. Immunol Res 22:177-190 
21. Levy O 2007 Innate immunity of the newborn: basic mechanisms and clinical correlates. Nat Rev Immunol 7:379-390

22. Cusumano V, Mancuso G, Genovese F, Cuzzola M, Carbone M, Cook JA, Cochran JB, Teti G 1997 Neonatal hypersusceptibility to endotoxin correlates with increased tumor necrosis factor production in mice. J Infect Dis 176:168-176

23. Ng PC, Li K, Leung TF, Wong RP, Li G, Chui KM, Wong E, Cheng FW, Fok TF 2006 Early prediction of sepsis-induced disseminated intravascular coagulation with interleukin-10, interleukin-6, and RANTES in preterm infants. Clin Chem 52:11811189

24. Wynn JL, Scumpia PO, Winfield RD, Delano MJ, Kelly-Scumpia K, Barker T, Ungaro R, Levy O, Moldawer LL 2008 Defective innate immunity predispose murine neonates to poor sepsis outcome but is reversed by TLR agonists. Blood 112:1750-1758

25. Genovese F, Mancuso G, Cuzzola M, Cusumano V, Nicoletti F, Bendtzen K, Teti G 1996 Improved survival and antagonistic effect of sodium fusidate on tumor necrosis factor alpha in a neonatal mouse model of endotoxin shock. Antimicrob Agents Chemother 40:1733-1735

26. Delfino D, Cusumano VV, Tomasello F, Cusumano V 2004 Beneficial effects of antibacterial peptide PR-39 in a neonatal murine model of endotoxic shock. New Microbiol 27:369-374

27. Walvatne CS, Johnson AS, Wojcik LJ, Cerra FB 1995 Cardiovascular response to acute and chronic endotoxemia in an awake, volume-resuscitated, canine model. Shock 3:299-306

28. Kaufmann A, Muhlradt PF, Gemsa D, Sprenger H 1999 Induction of cytokines an chemokines in human monocytes by Mycoplasma fermentans-derived lipoprotein MALP-2. Infect Immun 67:6303-6308

29. Casey LC, Balk RA, Bone RC 1993 Plasma cytokine and endotoxin levels correlate with survival in patients with the sepsis syndrome. Ann Intern Med 119:771-778

30. Nicoletti F, Mancuso G, Ciliberti FA, Beninati C, Carbone M, Franco S, Cusumano V 1997 Endotoxin-induced lethality in neonatal mice is counteracted by interleukin-10 (IL-10) and exacerbated by anti-IL-10. Clin Diagn Lab Immunol 4:607-610
31. Tomkiewicz RP, App EM, Coffiner M, Fossion J, Maes P, King M 1994 Mucolytic treatment with $\mathrm{N}$-acetylcysteine L-lysinate metered dose inhaler in dogs: airway epithelial function changes. Eur Respir J 7:81-87

32. Tirouvanziam R, Conrad CK, Bottiglieri T, Herzenberg LA, Moss RB 2006 Highdose oral $\mathrm{N}$-acetylcysteine, a glutathione prodrug, modulates inflammation in cystic fibrosis. Proc Natl Acad Sci U S A 103:4628-4633

33. Borgström L, Kågedal B, Paulsen O 1986 Pharmacokinetics of $N$-acetylcysteine in man. Eur J Clin Pharmacol 31:217-222

34. Tassani P, Barankay A, Haas F, Paek SU, Heilmaier M, Hess J, Lange R, Richter JA 2002 Cardiac surgery with deep hypothermic circulatory arrest produces less systemic inflammatory response than low-flow cardiopulmonary bypass in newborns J Thorac Cardiovasc Surg 123:648-654

35. Checchia PA, Bronicki RA, Costello JM, Nelson DP 2005 Steroid use before pediatric cardiac operations using cardiopulmonary bypass: an international survey of 36 centers. Pediatr Crit Care Med 6:441-444

36. Boodram S, Evans E 2008 Use of leukocyte-depleting filters during cardiac surgery with cardiopulmonary bypass: a review. J Extra Corpor Technol 40:27-42

37. Morris SJ 2001 Leukocyte reduction in cardiovascular surgery. Perfusion 16:371380

38. Paintlia AS, Paintlia MK, Singh AK, Stanislaus R, Gilg AG, Barbosa E, Singh 2004 Regulation of gene expression associated with acute experimental autoimmune encephalomyelitis by Lovastatin. J Neurosci Res 77:63-81

39. Fischer UM, Cox CS Jr, Laine GA, Mehlhorn U, Bloch W, Allen SJ 2007 Induction of cardioplegic arrest immediately activates the myocardial apoptosis signal pathway. Am J Physiol Heart Circ Physiol 292:H1630-H1633

40. Fischer UM, Cox CS Jr, Allen SJ, Stewart RH, Mehlhorn U, Laine GA 2003 The antioxidant $N$-acetylcysteine preserves myocardial function and diminishes oxidative stress after cardioplegic arrest. J Thorac Cardiovasc Surg 126:1483-1488 